\title{
Metastatik Mesane Kanseri Hastasına Cerrahi Yaklaşım: Metastazektomi ve Palyatif Sistektominin Yeri
}

\section{Surgical Approaches in Patients with Metastatic Bladder Cancer: Metastasectomy and Palliative Cystectomy}

\author{
Dr. Utku Lokman1,2, Dr. Özgür Uğurlu3 \\ 1Ankara Meslek Hastalıkları Hastanesi, Üroloji Kliniği, Ankara, Türkiye \\ 2Helsinki Üniversitesi Tıp Fakültesi, Üroloji Anabilim Dalı, Helsinki, Finlandiya \\ 3 Özel Akay Hastanesi, Üroloji Kliniği, Ankara, Türkiye
}

\section{Özet}

Mesane kanseri en sık ikinci rastlanan genitoüriner kanser olup; olguların \%30'unu kasa invaze mesane kanserleri oluşturmaktadır. Kasa invaze mesane kanseri hastalarında \%20 oranda metastatik ya da rezektabl olmayan hastalık mevcut olup, primer tedavi seçeneği sistemik kemoterapidir. Geriye kalan \%80'lik -metastatik olmayan ve rezektablhasta grubuna radikal sistektomi önerilmekte, fakat hastaların yarıya yakını, post-op takibinde karşımıza metastatik hastalıkla çıkmaktadır. Bu hasta grubunda da ilk seçenek yine kemoterapi olmaktadır. Güncel kemoterapi rejimleri ile bu hastalarda sağkalım oranları artmış olsa da; günümüz verileri, kemoterapi alan hastaların ancak \%50-\%70'inin tedaviye cevap verdiğini göstermektedir. Kemoterapi öncesi 3-6 ayın altında olan medyan sağkalım sürelerinin de, günümüz kemoterapi protokolleri ile 13-14 aya kadar çıkabildiği gösterilmiştir. Kemoterapiye cevap vermeyen hastalarda, radyoterapi ya da cerrahi gibi diğer tedavi yöntemleri gündeme gelmektedir. Kemoterapi sonrası ek tedavi arayışı, sadece kemoterapi cevabı olmayan hastalarda olmamaktadır. Kemoterapiye cevabı olan hastaların büyük bir kısmında da, rezidüel kiteler nedeniyle (parsiyel cevap) diğer tedavi yöntemlerine gerek duyulmaktadır. Ek olarak kemoterapiyle tamamen kaybolan kitlesi olan hastalarda da (komplet cevap), tümöral kitlenin olduğu alanda yüksek oranda görülen nüksler, yeni yaklaşımlar arama ihtiyacını ortaya koymaktadır. Vinflunin ikinci basamak kemoterapide başarı sağlamış olsa da, yapılan çalışmalar kemoterapi sonrası cerrahinin sağkalımı 2-3 kat kadar uzatabildiğini göstermektedir. Özellikle kemoterapiye cevabı iyi olan, sınırlı metastatik hastalığa sahip hastalarda cerrahiden fayda görme oranı daha yüksek görünmektedir. Ayrıca kemoterapi sonrası semptomatik durumda olan hastalarda da, cerrahinin hayat kalitesini arttırdığı görünmektedir. Palyatif sistektomi ise özellikle hematüri, ağrı ve irritatif işeme semptomlarına çözüm bulunamayan hastalara, son çare olarak önerilmektedir. (Üroonkoloji Bülteni 2014;13:75-78)

Anahtar Kelimeler: Metastatik mesane kanseri, metastazektomi, palyatif sistektomi

\begin{abstract}
Summary
Bladder cancer is the second most frequently diagnosed genitourinary malignancy and muscle-invasive bladder cancer accounts for $30 \%$ of the cases. $20 \%$ of muscle-invasive bladder cancer patients have metastatic or unresectable disease, which is primarily treated with systemic chemotherapy. Patients, who have non-metastatic and resectable disease, are directed to radical cystectomy; however, half of them progress, postoperatively, to metastatic disease. In this group primary treatment option is also systemic chemotherapy. Overall survival rates are increased after routine usage of modern chemotherapy protocols, but response rates to chemotherapy are not more than 50-70\%. Median overall survival rate is around 13-14 months, which was below the 3-6 months before these chemotherapy regimens. Alternative treatment options, such as radiotherapy and surgery, are discussed in non-responsive patients to chemotherapy. These treatment options are also discussed in partial responsive patients, due to residuel tumors. Complete responsive patients have also come up with relapses, which generally arise from the previous site of disease, thus need secondary treatment. Even though vinflunine seems to be an effective second-line chemotherapeutic drug, it is shown that post-chemotherapy surgery can increase overall survival up to 2-3 times than expected, especially in paitents who have limited metastatic disease and respond to chemotherapy. Post-chemotherapy surgery can also increase the quality of life in symptomatic patients. Palliative cystectomy is a last-choice treatment option in patients who have persistant hematuria, severe pain and irritative voiding symptoms. (Bulletin of Urooncology 2014;13:75-78)
\end{abstract}

Key Words: Metastatic bladder cancer, metastasectomy, palliative cystectomy 


\section{Giriş}

Mesane kanseri (MK), dünya çapında yılda 380,000'den fazla hastaya konulan yeni tanı ile en çok tanı konulan kanserler içinde dokuzuncu sıradadır. Yeni tanı alan hastalarda, tanı anında kas invaziv mesane kanseri (KIMK) saptanma oranı \%30 iken, metastatik KiMK saptanma oranı \%10-\%15 civarındadır (1). Küratif amaçlı yapılan radikal sistektomilerden sonra da hastaların yaklaşık \%30-\%50'sinde rekürrens tespit edilmektedir $(1,2)$. Rekürrens saptanan olgular incelendiğinde, bu olguların yalnızca \%25-\%30'unun pelvik bölgedeki lokal rekürrensler olduğu, \%70-\%75'inin ise uzak bölge rekürrensi olduğu görülmektedir (2). Bu durumun nedeni olarak KIMK tanısı alan hastaların yaklaşık üçte birinde bulunan saptanamamış metastazlar gösterilebilir.

Sistemik kemoterapi, özellikle 1980'lerde metotreksat, vinblastin, doksorubisin, sisplatin (M-VAC) rejiminin kullanıma sunulmasından sonra, metastatik KIMK'de altın standart tedavi yöntemi olarak tanımlanmıştır (3). M-VAC rutin kullanıma girdikten sonra yapılan çalışmalarda, yüksek doz MVAC (HD-MVAC) rejimi ile, granülosit koloni stimüle edici faktör (G-CSF) ile birlikte kullanılarak, daha az toksisite ile iki kat sisplatin ve doksorubisin dozu hastalara verilebilmiş, ve sağkalım sürelerinde artış sağlanabilmiştir. Ardından tanımlanan ve kullanıma giren gemsitabin sisplatin (GC) kemoterapisi, benzer onkolojik etkinliğe daha az yan etki (nötropeni ve mukozitis) ile ulaşabilmiştir. Ayrıca paklitakselin de GC kombinasyonuna eklendiği (PCG protokolü) çalışmalar da mevcuttur (4). Bu gelişmeler ışığında yapılan çalışmalar, kemoterapiye cevap oranının \%50-\%70'lere çıktığını gösterirken, medyan sağkalım süresini ise 13-14 ay olarak vermektedir (5). Kemoterapi sonrası komplet cevap, \%30'a yakın hastada sağlansa bile, bu hastaların çoğunda relapsa rastlanmaktadır (6); performans durumu iyi olan ve sadece lenf nodu metastazı olan hastalarda bile uzun dönem hastalıksız sağkalım oranları \%15'i geçmemektedir (1). İkinci basamak kemoterapide vinfluninin etkin olduğu gösterilmiş olsa da, relapsların büyük çoğunluğunun kemoterapi öncesindeki tümöral alanda saptanmakta olduğu bilgisi, kemoterapi sonrasındaki rezidüel kitlelere cerrahi girişim gerekliliği fikrini ortaya koymuştur (7).

\section{Metastazektomi}

Metastatik MK'de cerrahi konusunda yayınlanmış fazla sayıda çalışma bulunmamaktadır. Orteza ve ark.'nın 1971 yılında yayınladığı, pulmoner metastazektomiden sonra 5 yıllık sağkalım saptanmış vaka sonrasında (8), bu konudaki ilk seri Cowles ve ark. tarafından 1982'de yayınlanmıştır. Altı hastalık metastatik MK hasta grubunda torakotomi sonrası medyan sağkalım süresi 5 yıl olarak sunulmuştur (9).

1999 yılında Dodd ve ark. rezektabl olmayan ya da metastatik olan, M-VAC kemoterapisi alan 203 hastalarını retrospektif olarak incelemiş ve kemoterapi sonrası opere edilmiş 50 hastalık bir seri yayınlanmışlardır. Bu 50 hastanın 17'sinin patolojisi tümöral hücre açısından negatif gelmiş olup, komplet kemoterapi cevabı olarak değerlendirilmiştir. Üç hastada rezeksiyon sağlanamamıştır. Geriye kalan 30 hastada ise 5 yıllık sağkalımın, kemoterapiye tam cevap verenlerin sağkalımı ile benzer olduğu gözlenmiş (\%33 vs \%41); ve kemoterapiye iyi cevap veren, tümör yayılımı primer alana ya da lenf nodlarına sınırlı hastalarda cerrahinin fayda sağlayabileceği belirtilmiştir (10). Aynı klinikten, aynı yıl yazılmış diğer bir yayında, bu hastalardan Karnofsky performans skorunun (KPS) \%80'in altında olmasının ve visseral metastaz pozitifliğinin bağımsız kötü prognostik faktörler olduğu belirtilmiştir (11).

Otto ve ark.'nın 2001 tarihli faz 2 çalışmasında, sistemik tedaviye refrakter MK metastazlarında, rezeksiyonun performans skoruna etkisi araştırılmış, 51'i semptomatik, metastazektomi yapılan toplam 70 hastada, medyan sağkalım süresinin 7 ay olduğu bulunmuş; semptomatik hastalarda metastazektominin hayat kalitesini arttırdığı, fakat asemptomatik hastalarda, tersine, hayat kalitesinin düştüğü gösterilmiştir. Yorum olarak asemptomatik hastalarda metastazektominin önerilmediği belirtilmiştir (12).

Herr ve ark.'nın aynı sene yayınladıkları çalışmada, 207 rezektabl olmayan ya da lokal metastatik MK hastasının \%39'una kemoterapi sonrası cerrahi uygulanmış, ve bu hastaların verileri incelendiğinde, kemoterapiye parsiyel ya da komplet cevabı olmayan hastalarda cerrahinin ek fayda sağlamadığı gösterilmiştir. Yazarlar, kemoterapiye cevap veren; hastalığı mesane, rejyonel lenf nodları ve pelvis içinde sınırlı olan hastalarda cerrahiyi önermişlerdir (13).

Sweeney ve ark., 2003 yılında yayınladıkları makalede, retroperitoneal LN metastazı olan, kemoterapi sonrası retroperitoneal LN diseksiyonunun (RPLND) yapıldığı 11 hastalık serilerinde, özellikle 3'den az LN pozitifliği olan hastalarda, RPLND'nin küratif bir tedavi seçeneği olduğunu vurgulamışlardır (14).

2004 yılında yayınlanmış, MD Anderson Cancer Clinic datalarını sunan makalede, post-kemoterapi metastazektomi yapılan, 24'ü akciğere metastatik, toplam 31 hastada medyan sağkalım süresi 31 ay, 5 yıllık sağkalım oranı ise \%33 olarak bulunmuştur. $\mathrm{Bu}$ çalışmada Siefker-Radtke ve ark. seçilmiş hasta grubunda metastazektominin, kemoterapi ile birlikte etkili bir tedavi yöntemi olduğunu savunmuşlardır (6).

Abe ve ark., 48 hastalık metastatik MK serilerinde medyan sağkalım süresini 17 ay olarak belirtmişlerdir. Kırk sekiz hasta içinde, metastazektomi yapılan 12 hastalarında ise bu süre 42 ay olarak bulunmuştur. Bu hastalarda iyi performans durumu, sınırlı metastatik hastalık, komorbidite durumu, kemoterapiye cevap oranı gibi bias oluşturacak faktörler göz önüne alındığında bile, M-VAC kemoterapisi sonrası 13 ay olarak bilinen ortalama sağkalım süresinin 4 katı bir süreyi, cerrahinin etkisini dışlayıp, sadece bias faktörleriyle açıklayabilmek mümkün görünmemektedir (15).

Bu konudaki Almanya datalarını özetleyen 2009 yılında yayınlanmış makalede, Lehmann ve ark., metastazektomi yapılmış olan 44 hastanın sonuçlarını retrospektif olarak inceleyip sunmuşlardır. Beş yıllık sağkalım oranını \%28 olarak veren bu çalışma sonrası yazarlar metastazektomiyi, kemoterapi sonrasında sınırlı hastalığı olan, metastazektominin teknik olarak mümkün olabileceği küçük bir grup hastada önermişlerdir (2). Japonya'da yapılmış ve 2010'da yayınlanmış diğer bir çalışmada, son 20 yılda pulmoner metastazektomi yapılan 18 metastatik transizyonel hücreli karsinom (THK) hastası retrospektif olarak incelenmiş, ve medyan sağkalım süresi 52 ay olarak bulunmuştur. Soliter metastazlı hastaların 5 yıllık sağkalım oranı $\% 85,7$ iken multipl metastazı olan hastalarda bu oran $\% 20,0$ olarak saptanmış; ve yorum olarak özellikle soliter pulmoner metastazı olan hastalarda metastazektomi önerilmiştir (16). 
2011 yılında yayınlanmış başka bir çalışmada, Matsuguma ve ark., retrospektif olarak pulmoner metastazektomi yapılmış 32 hastanın verilerini inceleyerek 5 yıllık sağkalım oranını $\% 50$ olarak belirtmişlerdir. Bu oranın $3 \mathrm{~cm}$ 'den büyük metastazlarda $\% 10,3$ cm'den küçük metastazlarda \%65 olduğu vurgulanmış ve $3 \mathrm{~cm}$ 'den küçük soliter pulmoner lezyonlarda metastazektomi önerilmiştir (17).

2012 yilında Heidenreich ve ark., post-kemoterapi cerrahi ile sağkalımın 13 aydan 31-41 aya çıkabildiğini, özellikle kemoterapiye parsiyel cevap verip rezektabl hale gelen mesane tümörlerinde cerrahiyi önerdiklerini belirtmişlerdir. Yine de bu hasta grubunda, tedavi yönteminin hasta bazlı değerlendirilmesi gerektiği vurgulanmıs, stereotaktik radyoterapinin de bu hastalarda göz ardı edilemeyecek bir yöntem olduğuna vurgu yapılmıştır (18).

Abe ve ark.'nın 2014'te yayınladıkları diğer bir çalışma ise 4 Japon üniversitesinin verilerini sunmaktadır. Metastazektomi yapılan 42 metastatik MK hastasında medyan sağkalım 29 ay olarak bulunmuş, ve 5 yıllık sağkalım oranı \%31 olarak belirtilmiştir. Yazarlar, soliter LN ya da akciğer metastazı olan olgularda metastazektomiyi önermişlerdir (19).

Güncel EAU kılavuzunda, metastatik MK hastalarında, visseral metastaz varlığı ve performans durumu, primer bağımsız prognostik faktörler olarak kabul edilmektedir. Sekonder faktörler ise karaciğer metastazının varlığı ve düşük hemoglobin değeri $(<10 \mathrm{~g} / \mathrm{dL})$ olarak belirtilmektedir. Cerrahinin, parsiyel ya da komplet kemoterapi cevabı olan hastalarda, uzun-dönem hastalıksız sağkalımı arttırdığı belirtilmekle (Kanıt düzeyi: 3) birlikte, bu hastalarda cerrahi genel öneri olarak sunulmamakta, henüz algoritmalarda cerrahiye yer verilmemektedir (1). Buraya kadar yazılmıs olanlardan ortaya çıkan sonuç, metastazektomi hakkında netleşmiş kılavuz bilgilerinin ve ortak görüş bulmanın zor olduğudur. Bundan dolayı Herr'in, European Urology dergisinde yayınladığı derlemesinde metastazektomi için öne sürdüğü 6 kriter bu konuda önem taşımaktadır:

1. Metastatik MK olan hastalara öncelikle sistemik kemoterapi verilmelidir. Böylece metastazektomi endikasyonu ve cerrahi eksizyon sınırları daha net olarak ortaya konulmuş olur.

2. Kemoterapiye verilen, komplet ya da parsiyel, majör klinik yanıt, uzun dönem sağkalım için en önemli prognostik faktördür. 3. Sinırı lenf nodu (LN) tutulumu ya da soliter visseral lezyonu olan hastalar, özellikle de soliter pulmoner metastazı olanlar, metastazektomi için en uygun gruptur.

4. Birden çok organı tutan metastazlar, multipl karaciğer metastazları ve kemik metastazları kötü prognostik faktörlerdir. Komplet metastazektomi çoğunda sağlanamayacağı için genellikle önerilmez.

5. Metastazektomi kararı, teknik olarak cerrahisi mümkün vakalarda alınmalıdı; LN metastazlarında ikiden, visseral organ metastazlarında birden çok metastaz varlığında metastazektomiden kaçınılmalıdır.

6. Hastanın performans durumunun iyi ve agresif tedavi motivasyonunun olması sonucu pozitif yönde etkiler (20).

\section{Palyatif Sistektomi}

Lokal ileri MK'leri (özellikle T4b, pelvik ya da abdominal duvar tutulumu olan tümörler) hematüri, ağrı, disüri gibi hayat kalitesini oldukça etkileyen, persistan semptomlarla, hatta obstrüksiyona neden olmuş halde karşımıza çıkabilmektedir. Obstrüksiyon mekanik olarak gerçekleşebildiği gibi, tümör hücrelerinin üreter orifislerinini invaze ederek peristaltizmi engellemesi şeklinde de gerçekleşebilmektedir. Bu hastalarda tedavi yöntemleri küratif olmaktan çok palyatif anlam taşır. Palyatif radyoterapi özellikle pelvik ya da abdominal duvar tutulumu olan $\mathrm{T} 4 \mathrm{~b}$ hasta grubuna önerilmektedir. Sistektomi ve üriner diversiyon ise, uygulanabilecek hastalarda, en invaziv palyatif yöntemdir; morbiditesi yüksektir. Başka seçenek olmayan durumlarda uygulanmalıdır; bu hasta grubunda kesin tedavidense semptomatik gerileme amacı taşıdığı unutulmamalıdır. EAU kılavuzu 3 tane palyatif sistektomi endikasyonu sunmuştur (1):

1. Ciddi irritatif işeme semptomlarına neden olan ileri pelvik tümörler,

2. Ciddi ağrıya neden olan MK,

3. Transfüzyon gerektiren rekürren makrohematüri.

Yaş artııça palyatif sistektominin morbiditesinin de arttığı gösterilmiştir (21). Sistektomi yapılamayacak olan hasta grubunda ise üriner diversiyon, özellikle semptomlarına çare bulunamayan hastalarda, semptomları azaltmak, obstrüksyonu ortadan kaldırmak için son çare olarak uygulanabilir; morbiditesinin yüksek olduğu göz önünde bulundurulmalıdır. Bu hastalarda tedavi planlaması hasta ile detaylı bir şekilde görüşülerek verilmelidir. Seçilecek yöntemin morbiditesi göz ardı edilmeden, hastanın semptom durumu ve tedavinin/ semptomların hayat kalitesini etkileme durumuna göre, uygun yönteme, hasta ile birlikte karar verilmelidir. Devam eden klinik çalışmalarda, palyatif sistektomi sonrası adjuvan kemoterapi alan hastalar olsa da, adjuvan kemoterapi hakkında kabul edilmiş ortak bir görüş henüz mevcut değildir. EAU kılavuzu, neoadjuvan kemoterapi almamış hastalarda, lenf nodu pozitifliği mevcutsa, sisplatin bazlı kombinasyon kemoterapisini adjuvan olarak önermektedir (Öneri düzeyi: C).

\section{Sonuç}

Metastatik MK'de metastazektomi, sistemik kemoterapinin ardından tamamlayıcı bir tedavi yöntemi olarak seçilmiş hastalarda uygulanabilir. Hasta seçimi konusunda bir görüş birliği olmamasına karşın, kemoterapi cevabı iyi olan, soliter ve küçük metastazı olan, metastazektominin teknik olarak mümkün olduğu, performans durumu iyi hastalarda metastazektominin sağkalım süresini uzattığı söylenebilir. Semptomatik hastalarda metastazektominin hayat kalitesini arttırabildiği de gösterilmiştir. Yayınlanmış çalışmaların çoğunun retrospektif yapıda olması ve cerrahiye gidecek hasta seçimindeki muhtemel bias, bu konuda net yorum yapmamızı zorlaştırmaktadır; ayrıca yayınlardaki hasta sayısının az olması da başka bir handikap olarak karşımıza çıkmaktadır. Bu konuda yapılacak çok merkezli, randomize kontrollü, prospektif çalı̧malarla, metastazektominin sağkalıma etkisi daha açık bir şekilde ortaya konabilir. Palyatif sistektomi de, yüksek morbiditesi ile, özellikle semptomlarına çare bulunamayan hastalarda, son çare olarak seçilebilecek tedavi yöntemidir.

\section{Kaynaklar}

1. Stenzl A, Cowan NC, De Santis M, et al. Treatment of muscle-invasive and metastatic bladder cancer: update of the EAU guidelines. Eur Urol 2011;59:1009-1018.

2. Lehmann J, Suttmann H, Albers P, et al. Surgery for metastatic urothelial carcinoma with curative intent: the German experience (AUO AB 30/05). Eur Urol 200;55:1293-1299. 
3. Sternberg CN, Yagoda A, Scher HI, et al. M-VAC (methotrexate, vinblastine, doxorubicin and cisplatin) for advanced transitional cell carcinoma of the urothelium. J Urol 1988;139:461-469.

4. Calabro F, Sternberg CN. State-of-the-art management of metastatic disease at initial presentation or recurrence. World J Urol 2006;24:543-556.

5. Svatek RS, Siefker-Radtke A, Dinney CP. Management of metastatic urothelial cancer: the role of surgery as an adjunct to chemotherapy. Can Urol Assoc J 2009;3:S228-231.

6. Siefker-Radtke AO, Walsh GL, Pisters $L L$, et al. Is there a role for surgery in the management of metastatic urothelial cancer? The M. D. Anderson experience. J Urol 2004;171:145-148.

7. Dimopoulos MA, Finn L, Logothetis CJ. Pattern of failure and survival of patients with metastatic urothelial tumors relapsing after cis-platinumbased chemotherapy. J Urol 1994;151:598-600; discussion 600-601.

8. Orteza AM, Kandzari SJ, Milam DF. Transitional cell carcinoma of the bladder with pulmonary metastasis: case report on 5-year survival following resection of metastasis. J Urol 1971;105:232-235.

9. Cowles RS, Johnson DE, McMurtrey MJ. Long-term results following thoracotomy for metastatic bladder cancer. Urology 1982;20:390-392.

10. Dodd PM, McCaffrey JA, Herr H, et al. Outcome of postchemotherapy surgery after treatment with methotrexate, vinblastine, doxorubicin, and cisplatin in patients with unresectable or metastatic transitional cell carcinoma. J Clin Oncol 1999;17:2546-2552.

11. Bajorin DF, Dodd PM, Mazumdar $M$, et al. Long-term survival in metastatic transitional-cell carcinoma and prognostic factors predicting outcome of therapy. J Clin Oncol 1999;17:3173-3181.

12. Otto $T$, Krege $S$, Suhr J, Rubben $H$. Impact of surgical resection of bladder cancer metastases refractory to systemic therapy on performance score: a phase II trial. Urology 2001;57:55-59.
13. Herr HW, Donat SM, Bajorin DF. Post-chemotherapy surgery in patients with unresectable or regionally metastatic bladder cancer. J Urol 2001;165:811-814.

14. Sweeney $P$, Millikan $R$, Donat $M$, et al. Is there a therapeutic role for post-chemotherapy retroperitoneal lymph node dissection in metastatic transitional cell carcinoma of the bladder? J Urol 2003;169:2113-2117.

15. Abe T, Shinohara N, Harabayashi T, et al. Impact of multimodal treatment on survival in patients with metastatic urothelial cancer. Eur Urol 2007;52:1106-1113.

16. Kanzaki R, Higashiyama M, Fujiwara A, et al. Outcome of surgical resection of pulmonary metastasis from urinary tract transitional cell carcinoma. Interact Cardiovasc Thorac Surg 2010;11:60-64.

17. Matsuguma $H$, Yoshino $I$, Ito $H$, et al. Is there a role for pulmonary metastasectomy with a curative intent in patients with metastatic urinary transitional cell carcinoma? Ann Thorac Surg 2011;92:449-453.

18. Heidenreich A, Wilop S, Pinkawa M, Porres D, Pfister D. Surgical resection of urological tumor metastases following medical treatment. Dtsch Arztebl Int 2012;109:631-637.

19. Abe T, Kitamura H, Obara W, et al. Outcome of metastasectomy for urothelial carcinoma: a multi-institutional retrospective study in Japan. J Urol 2014;191:932-936.

20. Herr HW. Is metastasectomy for urothelial carcinoma worthwhile? Eur Urol 2009;55:1300-1301.

21. Zebic N, Weinknecht S, Kroepfl D. Radical cystectomy in patients aged $>$ or $=75$ years: an updated review of patients treated with curative and palliative intent. BJU Int 2005;95:1211-1214. 